\title{
Cultura y modernización de la pesca artesanal en Chile: Adaptaciones, cambios e hibridaciones en una caleta de algueros
}

\section{William Marín A.}

Magíster en Antropología y Desarrollo - Universidad de Chile

Asistente Social - Universidad Tecnológica Metropolitana

Docente Universidad de Atacama, Chile

williamarin@hotmail.com

Resumen

El propósito del presente artículo es identificar y analizar los contenidos del discurso de los algueros de Caleta Los Bronces referido a las adaptaciones, cambios y consecuencias de la modernización en la dimensión cultural del subsector pesquero artesanal.

Abstract

The purpose of this article is to identify and analyze the contents of the speech of algueros of Caleta Los Bronces referred to the adjustments, changes and impact of modernization on the cultural dimension of the artisanal fisheries sub-sector.

Palabras Clave: Cultura, Modernización, Hibridación, Pesca Artesanal, Constructivismo

\section{Proceso de modernización chileno en los últimos treinta años}

La caracterización del contexto global de transformaciones sociales y económicas que ha vivido Chile en los últimos treinta años constituye el tipo de debate en el que adquiere sentido el tema de este artículo. El conjunto de medidas estructurales impulsadas desde el Estado y el sector privado, adaptativas al modelo económico neoliberal, se manifiesta a nivel de espacios centrales y periféricos, urbanos y rurales, generando cambios que afectan positiva y negativamente al conjunto de la sociedad chilena, como por ejemplo, la privatización de la seguridad social, previsión y salud, a inicios de los años 80 del siglo recién pasado, y la apertura de mercados y reducción de aranceles a las importaciones; se manifiesta también en la precarización de las relaciones laborales, la modernización de la infraestructura y gran desarrollo tecnológico de los medios de comunicación e información, entre muchas otras transformaciones, que localmente y a nivel sectorial en el mundo de la pesca artesanal, repercuten en la mayor regulación y formalización del sector, la privatización de los recursos marinos y la promoción de la idea de sustentabilidad económica y ambiental en las actividades pesqueras extractivas. Sin embargo, a mas de treinta años de iniciado dicho proceso modernizador, se observan discursos en el entorno experto que dan cuenta de que la cultura pesquera extractiva artesanal coexiste con una cultura sustentable moderna en construcción, en la cual se observan circuitos híbridos con lo tradicional. Las prácticas sociales recurrentes, modos de organización, técnicas de extracción, comercialización, entre otros procesos, se ven 
influidas por las consecuencias de formas de vida introducidas por los procesos de modernización, contexto en el cual surge y se consolida un orden social capitalista.

Según Hernández \& Thomas (2001), en las dos últimas décadas del siglo XX, el impacto mundial de la globalización ha provocado profundos cambios en las sociedades, sobre los sistemas económicos, políticos y culturales. La modernidad sobrevalora patrones culturales del Primer Mundo, y por el contrario, se generan fenómenos de subvaloración de lo tradicional, lo local, lo rural, base de su patrimonio cultural produciendo un debilitamiento de las identidades latinoamericanas.

El encuentro de modos productivos, tradicionales y modernos, que se describen al inicio de este texto, y la tensión entre lógicas distintas y el tipo de resultados que alcanzan, se puede abordar teóricamente siguiendo los planteamientos de García Canclini (1990). Este autor señala que la incertidumbre acerca del sentido y el valor de la modernidad deriva en cruces socioculturales en que lo tradicional y lo moderno se mezclan. La modernización en Latinoamérica mas que una fuerza ajena y dominante que operaría por sustitución de lo tradicional, se concibe como los intentos de renovación con que diversos sectores se hacen cargo de la heterogeneidad multitemporal de cada nación.

La globalización ha llegado a los distintos espacios locales chilenos, provocando transformaciones en sus modos de producción y redes de intercambio tecnológico y comercial, generando consumos creativos de lo novedoso del proceso modernizador, adaptando bienes y mensajes a su propia realidad. En este sentido, Margulis (2005) señala lo siguiente:

Uno de los grandes temas que plantea la globalización en el plano de la cultura: la intersección de lo global con lo local, el nivel de las identidades, su evolución y nuevas formas de emergencia, la hibridación... También, es preciso tomar en cuenta la forma en que la cultura local incorpora la novedad, cómo la interpreta y le asigna un lugar en su trama de significados. Los consumos no son uniformes, el consumo de bienes, al igual que el consumo de mensajes, suele ser creativo: la gente decodifica productos y mensajes en el marco de su cultura local, sus condiciones de vida y de relación y su capital simbólico. (pp.34)

De acuerdo a Larraín (1997), a partir de la implementación de las Teorías Neoliberales de libre mercado a finales de los años 70 del siglo XX., se produjo importantes cambios en la estructura socioeconómica Latinoamericana. La idea que se instala es la apertura de los mercados, la exportación de materias primas a países industrializados, entre otras.

Desde la perspectiva económica de French-Davis, R. (1999), la estrategia neoliberal impulsada en Chile desde el gobierno dictatorial de Pinochet (1973-1990), tuvo como preocupación central controlar los desequilibrios macroeconómicos y la hiperinflación, y posteriormente la preocupación se trasladó a la ineficiencia del sistema económico, implementando una serie de reformas como la eliminación de controles de precios, apertura indiscriminada de las importaciones, liberalización del mercado financiero, reducción del tamaño del sector público, privatización de empresas estatales, entre otras. Las exportaciones no tradicionales registraron un crecimiento promedio anual de 
$14,5 \%$ entre 1974 y 1989. Sin embargo, “... la modernización estuvo asociada a un crecimiento económico bajo, de sólo 2,9\% entre 1974 y 1989" (Ffrench-Davis, R., 1999, p. 34). Algunas de las modernizaciones económicas que se produjeron y que pueden destacarse son, el significativo crecimiento y diversificación de las exportaciones, el ordenamiento del presupuesto fiscal, y el nacimiento de una nueva y mas dinámica generación empresarial.

Desde la perspectiva de la Nueva Historia Social, Salazar, G., (1999) señala que, "la obra gruesa de la 'modernización' fue la misma construcción del Estado Neoliberal, que eliminó un 'estorbo' e instaló un 'instrumento' para la acumulación del capital" (p.109). La modernización consistió en una redistribución de mecanismos acumulativos, es decir privatización del Estado Desarrollista, que incluye empresas estatales, servicios públicos de salud, educación, previsión, entre otros. "La lógica de las modernizaciones introducidas por el Estado Neoliberal no tiene, pues, una carácter social ni civil, sino exclusivamente económico"(Salazar, 1999, p. 111).

Desde el año 1975, y según Moulian, T. (2001) en Chile en el marco de una economía abierta, reducción de aranceles, se produjo primero un proceso de desindustrialización dado que la industria local no soportó lo drástico del cambio en las políticas económicas. Solo posteriormente a la crisis del año 1982, se observa una lenta reindustrialización, reorganización del mercado interno y aumento progresivo de las exportaciones manufactureras. Ahora se actúa en un mercado globalizado que regula los movimientos del mercado interno que depende en gran parte de su competitividad. A partir de 1985 la economía chilena entró en un círculo virtuoso en la tasa de crecimiento del PIB, que ha durado hasta 1995. Entre 1985 y 1989, el crecimiento alcanzó el 6,4\%, y entre 1989 y 1993 alcanzó el 6,3\% (Moulian, T., 2001, p.4. Fuente: Banco Central: indicadores... 1990; Meller, P., en Apuntes Cieplan, №118,1993).

El crecimiento económico sostenido ha sido un factor importante en la reducción de la pobreza en Chile. Según Contreras, D. (1996), haciendo uso de datos correspondientes a los años 1987, 1990 y 1992, si se observa la evolución de la pobreza y la desigualdad, en el período 1987-1992, disminuyó la pobreza y experimentó una evolución dispareja de la desigualdad. Este período es importante porque el país cambia de un régimen autoritario a uno democrático, al menos en su forma, y se profundiza la implementación de programas sociales destinados a reducir la pobreza. Durante el último período del régimen militar, entre 1987 y 1990, Chile experimentó un rápido crecimiento económico, disminución de la pobreza y aumento de la desigualdad. Bajo el régimen democrático iniciado en 1990, y en particular la región III, experimentó una disminución de la pobreza y la desigualdad, jugando el crecimiento económico un papel importante en la reducción de la pobreza. Otro factor que afecta la pobreza es la desigualdad, en la cual la gente se encuentra privada de consumir productos o participar en actividades, en relación al resto de la sociedad. Por otra parte la heterogeneidad regional da cuenta de la ausencia de una relación entre pobreza, desigualdad y bienestar. El retorno de la educación y las políticas económicas implementadas por el primer gobierno de la Concertación, según Contreras, tiene un rol importante en la explicación de la evolución dispar de las economías regionales. El sistema económico estaría generando incentivos para mejorar la calidad y cantidad del capital humano. 
Según Salazar, G., (1999), la transición desde la dictadura neoliberal hacia la democracia neoliberal tiene tres lógicas distintas: la de la clase política militar, la de la clase política civil, y la de la sociedad civil. Para la primera, la transición se inició cuando y donde su 'poder de fuego' perdió efectividad política, por lo cual la 'retirada exitosa' era lo aconsejable para que el modelo instaurado no perdiera legitimidad, apoyado en el artefacto constitucional de 1980, el cual sirvió de señuelo para atraer a la clase política civil para administrar la continuidad del modelo neoliberal. Para la segunda, la clase política civil, desde 1985, la renovada izquierda socialista teoriza sobre los escenarios posibles de transición a la democracia, asumiendo quizás por temor, el camino legalista de respeto constitucional, por sobre el histórico del movimiento social. Por último, para la sociedad civil, el modelo administrado desde 1990 por la clase política civil, progresivamente pierde legitimidad, y paralelamente emerge una red ciudadana lateral, autónoma, localizada y globalizada, de efectos históricos trans-liberales, que da cuenta de la resiliencia de la sociedad civil.

De acuerdo a Mascareño, A. (2001), la transición al nuevo milenio fue el mercado, libre y autónomo. La sociedad del conocimiento se perfila como posibilidad a comienzos del siglo XXI, la cual promueve una sociedad descentralizada, interconectada e interdependiente en sus diversas funciones y operaciones. "El rasgo central de una sociedad fundada en el conocimiento está en que el núcleo de sus estructuras y procesos simbólicos y materiales depende de operaciones donde el saber es imprescindible y la ignorancia ${ }^{1}$ inaceptable" (Mascareño, A. 2001), paralelamente los sistemas integrados y el análisis experto son altamente relevantes como factores productivos. En este contexto, se perfila la nueva economía.

A partir de este contexto de globalización y modernización se plantea una serie de requerimientos a la sociedad chilena que son impulsados por el Estado por medio de la implementación de diversas políticas públicas y adaptación de su estructura burocrática.

Un ejemplo de lo anterior es la transformación del Estado, que se comprende como una respuesta funcional a los desafíos que la dimensión económica de la globalización impone (Torres-Rivas, E., 1995; en Santibáñez, D.,2000).

Otro ejemplo del tipo de cambios al que se alude, pero generado mas bien desde el sector privado, corresponde a la expansiva diversificación de los medios masivos de comunicación, colaboradores en la construcción de opinión pública, y en particular la incorporación de una nueva tecnología como la televisión satelital y la masificación de la red Internet, lo cual ha conllevado a la diversidad en el manejo y difusión de la información, generando con ello la construcción de realidades múltiples. Así mismo, el acceso a nuevas tecnologías de la información, en el sector productivo, ha permitido mejorar los niveles de competitividad de las empresas locales. Según lo establece el Informe de Desarrollo Humano en Chile, del PNUD (2002), uno de los cambios en el contexto que condicionan la producción cultural actual, es la mediatización de la comunicación social, las TIC cambian los mapas mentales que se usan para ordenar y clasificar nuestra realidad social.

De acuerdo a lo anterior, los cambios de carácter global se traducen en términos nacionales y locales en estrategias que impactan a la población en términos de una experiencia de cambio cultural y de prácticas sociales diversas. 
Desde una visión critica del proceso de modernización impulsado en Chile a partir del año 1975, Salazar, G., (1999), plantea que la instalación del Estado Neoliberal, en la que la clase político-militar fue un actor hegemónico, en rigor fue una 'contrarevolución militar', anti-proletaria en el corto plazo y, en el mediano, pro-capitalismo internacional. Sin embargo, desde la perspectiva económica, ha sido una 'revolución capitalista', siendo mas mercantil que productiva, privilegiando el mercado exterior, lo cual conlleva una reactivación del sector primario exportador, con consecuencias negativas en la conservación de recursos naturales, y a la vez, una consolidación del sector mercantil-financiero de control extranjero. El dispositivo jurídico que posibilita la implantación del modelo neoliberal en Chile, corresponde a la Constitución de 1980 (mecánica e instrumental), la cual garantiza la gobernabilidad de la sociedad, (seguridad y orden interior mediante el terrorismo de Estado), y la reproductibilidad de las bases de la institucionalidad. En otro ámbito, el de la modernización de las relaciones laborales, (empleo flexible) se ha precarizado el empleo, sin contrato o con contrato temporal, sin previsión, sin sindicalización, sin capacitación, etc.

A la vez, desde una posición crítica Ffrench-Davis, R., (1999), señala que al final del régimen de Pinochet, entregaba una economía con un gran impulso exportador y una parte del sector productivo modernizada, pero con desequilibrios macroeconómicos, y en los distributivo una gran desigualdad social. En su origen, el modelo impuesto en Chile que se inicia en 1973 y concluye en 1982, representa el ejemplo de mayor ortodoxia neoliberal de estrategias a las cuales los países en desarrollo podían recurrir entonces. Se identifican tres áreas estratégicas que al experimento neoliberal le impiden funcionar eficazmente: la heterogeneidad de las estructuras productivas, problemas sectoriales y regionales, constituyen obstáculos para las políticas económicas globales; la desventaja competitiva entre agentes económicos conduce a que la liberalización y privatización acentúe la concentración del poder económico; y el contexto macroeconómico creado por el monetarismo-ortodoxo ha hecho que las tendencias desestabilizadoras y asimétricas en los procesos de ajuste resulten procíclicos, con alto costo social y económico.

Según Tironi, E. (1990) el tipo de modernización chileno ha generado una severa segmentación de la estructura social, lo cual conlleva una ampliación de los sectores marginales, y una diferenciación interna en sus canales de integración social, reducción de la clase obrera, diferenciación del empresariado según el tamaño de las industrias y la actividad económica, quiebre de la clase media con un segmento asalariado en declinación y otro independiente en ascenso. "En el caso de Chile, a lo menos, no es posible distinguir un sector moderno central y otro tradicional periférico; tampoco se percibe un proceso paulatino de incorporación del segundo al primero" (Tironi, 1990). En definitiva, según este autor no se reconocen tendencias que apunten a la configuración progresiva de una sociedad que se homogeneiza en torno al patrón moderno. Lo que caracterizaba a la sociedad chilena a comienzos de la década del noventa del siglo $X X$ era su fuerte segmentación interna y progresiva institucionalización de esta estructura social.

Otro punto de vista crítico corresponde al informe del PNUD que hace diez años señalaba que el proceso de modernización impulsado en Chile, presenta un déficit en torno al reconocimiento de la diversidad cultural y las diferentes subjetividades que se entretejen en un espacio socio productivo local, lo cual repercute finalmente en los 
niveles de satisfacción y seguridad humana que los actores sociales perciben ${ }^{2}$. Esta tensión entre modernización y subjetividad se entiende a partir de la expansión del cálculo medios-fines a los diversos campos de la vida social, si no son puestos en relación con la dimensión subjetiva del desarrollo. "Los cambios registrados en los últimos años afectan especialmente la vida cotidiana de la gente y su sociabilidad, con sus tejidos familiares y comunitarios, sus valores e identidades" (PNUD, 1996).

Por otro lado, el informe de 1998 intenta comprender el sentido y orientación de la modernización en marcha y su impacto en la vida cotidiana de la gente y su sociabilidad. A la vez señala que se observa un malestar posiblemente derivado de que los mecanismos de seguridad que ofrece el actual "modelo de modernización" resultan insuficientes o ineficientes. A pesar de los éxitos obtenidos, la seguridad humana en Chile no tendría un nivel satisfactorio y se encontraría distribuida de manera desigual. ${ }^{3}$

A partir de las diferentes visiones presentadas sobre el proceso modernizador chileno, a continuación se describen los principales cambios implementados en el sector público, y particularmente en la regulación del sector pesquero artesanal, en los últimos quince años aprox.

\section{Modernización de la gestión pública y el sector pesquero artesanal, en período de transición democrática : 1990 - 2006}

En Chile, desde comienzos de los años 90 del siglo $\mathrm{XX}$, los requerimientos modernizadores plantean modificaciones en la política de gestión de recursos naturales, las cuales han influido en la transformación que afecta al sistema pesquero tradicional.

La regulación del sector pesquero artesanal, se da en un contexto de gobernabilidad democrática y modernización de la gestión pública, que “implica adecuar las estructuras del aparato público, en particular la de los servicios públicos, a las actuales exigencias de transformación y dinamismo del Estado. La nueva relación entre democracia, Estado, mercado y sociedad civil implica ajustar el pensamiento, las estrategias y los estilos de trabajo a los desafíos que impone el nuevo milenio" (Ramírez, 2001, p. 2) . Para este autor la modernización se refiere a la lógica instrumental - calculativa (medios a fines), y el control de los procesos sociales y naturales.

El paso de un régimen pesquero de libre acceso (tradicional) a uno con regulaciones (moderno) trae consigo un cambio de normativas necesarias para resguardar el capital natural. Los pescadores artesanales deben ahora formalizar su actividad y cumplir exigencias legales que responden a medidas de gestión de recursos hidrobiológicos y a la regulación impulsada por la institucionalidad pública, en 1991, con la promulgación de la Ley General de Pesca y Acuicultura. Desde su implementación, en un contexto de re-democratización del país, Reforma del Estado, y profundización del modelo económico neoliberal, se observan diversos discursos que dan cuenta de cambios en los modos de vida de los pescadores artesanales. Sin embargo, desde el entorno experto no se observa una sistematización de los mismos, y un análisis que de cuenta de los éxitos y fracasos de esta experiencia, así como los efectos en la dimensión cultural del modelo modernizador. 
Para comprender mejor el tránsito vivenciado por los algueros desde una actividad de libre acceso, informal e individual a una actividad regulada, que promueve el asociativismo en las formas de organizar el trabajo, es necesario señalar la importancia de la aplicación de la Ley General de Pesca y Acuicultura (Ley 18.892, establecida por el Decreto Supremo 430, de 1991), que "introdujo una serie de elementos ordenadores que han permitido controlar el incremento de la actividad pesquera sin afectar significativamente la sustentabilidad de los recursos hidrobiológicos" (CONAMA, 1997, p.20). Dicho texto legal define conservación como el uso presente y futuro, racional, eficaz y eficiente de los recursos naturales y su medio ambiente. Define pesca artesanal como la actividad pesquera extractiva realizada por personas naturales que en forma personal, directa y habitual trabajan como pescadores artesanales. Para los efectos de esta ley, se distinguirá entre armador artesanal, mariscador, alguero y pescador artesanal propiamente tal. Se considerará también como pesca artesanal, la actividad pesquera extractiva que realicen personas jurídicas. Alguero: es el pescador artesanal que realiza recolección y secado de algas, con o sin el empleo de una embarcación artesanal. A la vez se define un régimen denominado Áreas de Manejo y Explotación de Recursos Bentónicos, al que podrán optar las organizaciones de pescadores artesanales legalmente constituidas. Estas áreas serán entregadas mediante resolución del Servicio Nacional de Pesca, previa aprobación por parte de la Subsecretaría de un proyecto de manejo y explotación del área solicitada, a través de un convenio de uso hasta de cuatro años, renovable conforme al mismo procedimiento. Promueve una explotación sustentable mediante cuotas biológicamente aceptables. La institucionalidad la compone la Subsecretaría de Pesca, la cual formula la política pesquera y las medidas de administración de las pesquerías; y el Servicio Nacional de Pesca, el cual fiscaliza y controla el cumplimiento de las medidas adoptadas; ambos organismos son dependientes del Ministerio de Economía.

El contexto institucional descrito y la mayor regulación del sector pesquero artesanal y el predominio de la lógica económica que la sustenta, se vincula con lo planteado en un artículo por Santibáñez, D. (2000), sobre modernización de la gestión pública en Chile, en el cual se describe parte de las características del proceso de modernización que pone de manifiesto la potencia de la lógica del mercado y el enfoque de la administración empresarial. Según Santibáñez, la Organización para la Cooperación y el Desarrollo Económico (OCDE) que reúne a los países más industrializados del planeta se ha transformado, para el caso chileno, en una importante caja de herramientas para impulsar su estrategia de modernización. Las estrategias de modernización de la gestión pública se conciben como un conjunto de reformas orientadas a posibilitar el despliegue de la capacidad emprendedora de la empresa privada.

Los requerimientos modernizadores, expresados en los programas desarrollados por las instituciones públicas de fomento para la pesca artesanal ${ }^{4}$ (CORFO, SERCOTEC, SERNAPESCA, SENCE, FOSIS, DOP, entre otras), han promovido el equipamiento, capacitación, y asistencia técnica para el fortalecimiento organizacional, la búsqueda de nuevos mercados y comercialización en forma asociativa para permitir la obtención de mejores precios para su producción.

Este nuevo escenario opera cambios culturales en el mundo de la pesca artesanal en nuestro país en el marco de los procesos antes descritos. La política social y económica impulsada y gestionada desde el Estado, no es neutra en términos de los valores e 
ideas que sustentan su intervención. La homogeneización de los programas diseñados y ejecutados por el aparato gubernamental, de manera centralista, se vinculan con mayores grados de impertinencia cultural frente a la diversidad de realidades locales. Los patrones culturales impulsados por la modernización se tensionan con la especificidad de localidades distantes vinculadas a modos de vida tradicionales identificados con una cultura de tipo extractiva, en la cual la competencia y el individualismo en faenas caracterizan las relaciones entre los actores sociales presentes.

De acuerdo a Solé, C., (1998) los antropólogos toman la gran diversidad de las sociedades tradicionales para explicar primeramente un proceso de cambio social. Por lo anterior, la modernización como tipo de cambio social presentará características distintas de una sociedad a otra. Según Brunner, J., (1990):

El cambio social "es" la sustancia misma de la Sociedad...La democracia, en tanto diferencia y especializa la política, "libera" a los demás subsistemas de la sociedad, permitiéndoles aumentar su complejidad y su potencial de respuesta, cambio y adaptación, a la vez que somete al propio proceso político a un constante juego reglamentado de oportunidades de cambio. Por otro lado, en la medida que la democracia se asocia al mercado..., ella limita las posibilidades de incidencia de las "políticas de cambio en el plano económico" al sistema de castigos inherente al mercado. Este último se hace cargo de coordinar las dinámicas principales de la economía, "liberándola" del comando político, o sea, de los funcionarios y del Estado... Con todo, incluso en este momento de rápida expansión de los fenómenos de globalización internacional de la economía, el mercado no puede proveer la metacoordinación de las sociedades organizadas como Estado-naciones en sus respectivos espacios de control...El cambio social y la democracia son compañeros sólo en la sociedad que los produce, y llegan a serlo a través de dos instrumentos encontrados: el mercado y la política... ( $p p$. 246-247)

Según Ruiz, A., (2002) el biólogo chileno Humberto Maturana "sostiene que una cultura es una red cerrada de conversaciones y que el cambio cultural ocurre cuando se produce un cambio de conversaciones en esa red; cambio que surge, se sostiene y mantiene en el emocionar de los miembros de la comunidad" (p.6)

Las estrategias de intervención impulsadas por el Estado, no son neutras puesto que implican exigencias de cambio de conductas y modos de ver. Por ejemplo un programa denominado Profesionalización de la Pesca Artesanal, financiado por SERCOTEC-FOSIS, cuyo objeto es traspasar competencias para un adecuado desempeño productivo, "que derive en un proceso de transformación cultural acompañado de la presencia de un espíritu emprendedor, que impacte social y económicamente las comunidades de pescadores artesanales" (Gobierno de Chile, 2005), en éste se plantea un cambio cultural dirigido desde el Estado para adaptar a un sector de la población a la lógica del mercado competitivo.

La modernización neoliberal impulsada en las últimas tres décadas posiciona la lógica de mercado expresada en comportamientos de consumo de bienes y servicios (tangibles e intangibles) contexto en el cual el dinero (ganancia y rentabilidad) como forma de pago se constituye en el mecanismo eje que articula formas y volúmenes de 
trabajo y producción, determinando de alguna manera los modos de vida coherentes y adaptables a este nuevo escenario de modernidad.

Se observa cierta incapacidad de las políticas sociales de adaptarse a los cambios socioculturales en el sentido de no reconocer elementos de lo tradicional como mecanismos de obstaculización o facilitación de procesos modernizadores del aparato productivo, desconociendo muchas veces las prioridades de las necesidades locales. Esta reflexión se observa en De Laire (2002):

En Caleta Chipana el Estado invirtió un millón de dólares en infraestructura portuaria, con escasa consulta a los beneficiarios para su construcción, los que, siendo iletrados muchas veces, tienen sin embargo un conocimiento práctico del terreno que ninguna expertise profesional puede pasar por alto. Resultado: en ciertos momentos, bajo ciertas condiciones de marea, el muelle queda en seco... Segundo caso: en el muelle de Pisagua el Estado instaló un moderno pescante destinado a facilitar la descarga desde los botes. Los ejecutores del proyecto no sólo consultaron poco, sino que instalaron el pescante con una cadena cuya altura no llega al nivel de los botes, es decir, no sirve para nada tal cual está. Por otro lado, los pescadores se quejan amargamente del hecho que, aun resolviendo ese problema, las barras laterales que permitirían girar el eje manualmente para realizar la maniobra de descarga están situadas a más de dos metros de altura. Absurdo de la situación: cual elefante blanco, el pescante moderno sirve de adorno en el muelle, mientras los pescadores descargan con un pescante que data de fines del siglo XIX, que funciona muy bien $y$, de paso, tiene las aludidas barras laterales para hacer girar el eje a una altura razonable, del orden del metro treinta. (p.143)

De igual forma se tiende a la implantación de modelos de administración y técnicas de trabajo ajenas a la cultura tradicional, generando formas de hibridación desequilibrada que responden a lógicas de dominación o colonización cultural, mas que a la generación de un proceso de cambio cultural en conjunto con los actores sociales involucrados. En esta perspectiva, el individualismo en faenas se contrapone a la exigencia asociativa del modelo modernizador. La informalidad de las relaciones sociales tradicionales colisiona con los requerimientos modernizadores de formalización y regulación del sector.

La tendencia a la homogeneización en la implementación de programas sociales del Estado, no permite reconocer la diversidad cultural, cayendo en prácticas impertinentes según los espacios socio productivos locales, ignorancia usando la terminología de Mascareño, A. (2001), puesto que se configura un saber inadecuado al espacio de intervención.

Lo anterior se ejemplifica en programas como el Fondo de Fomento para la Pesca Artesanal, que en el pasado, ha financiado proyectos que buscando la diversificación productiva de buzos mariscadores, ha promovido la utilización de aparejos de pesca como el espinel (cordel de nylon al cual cada cierta distancia se conectan líneas cortas de nylon llamadas reinales, las que en su extremo llevan anzuelos con carnada, se tiran al mar amarrado a boyas), no siendo utilizados finalmente. Las críticas a la focalización del gasto social, se sustentan en experiencias como éstas, que se repiten en otras actividades económicas como la agropecuaria, a través de programas 
gubernamentales del INDAP, y programas de capacitación laboral ejecutados por el SENCE, que no han respondido a las necesidades del mercado a nivel local o regional, y a las expectativas de inserción laboral de sus 'beneficiarios'.

A partir de este contexto y a modo de síntesis y problematización, se puede plantear que estamos frente a un proceso de modernización con determinadas características (neoliberal, economicista, etc.). Este proceso de modernización se realiza en el marco de una modernidad latinoamericana sui generis: descrita como modernidad híbrida. Así ha sido siguiendo la tesis de Garcia Canclini. Este nuevo proceso de modernización introduce nuevas complejidades, esta modernidad híbrida, y provoca cambios en todos los ámbitos de la vida social y cultural. A partir de lo anterior se analiza un proceso de cambio específico, que corresponde al paso de un "modo de producción de carácter extractivo" que hemos denominado cultura extractiva competitiva, porque visualizamos sus consecuencias en las prácticas sociales y de vida, cuyas principales características se vinculan con el modo de producción: individual, competitivo, no planificado, comercialización dependiente, etc. Todo ello tiene consecuencias en el ámbito de la vida de los algueros. Puede responder a adaptaciones necesarias, (vida en rucos, etc.) y consecuencias naturales (sobreexplotación de los recursos marinos), a un modo de producción regulado, que promueve la lógica asociativa, que también tendrá consecuencias. Los modos de producción son formas propias de un tipo de modernidad. El segundo modo de producción (que hemos denominado cultura sustentable asociativa) es propio de un tipo de modernización. Lo que se tensiona son estos modos de producción y sus particulares efectos culturales.

Las exigencias de cambio cultural de los programas de modernización del sector pesquero artesanal, su lógica y orientación, colisionan con ciertos aspectos de la sociedad tradicional expresada en la cultura extractiva de los pecadores artesanales, sus creencias, valores, relaciones sociales y modos de producción.

A continuación nos proponemos conocer como impactan las estrategias de intervención de las políticas públicas en un caso específico de experiencias de modernización, en una caleta de algueros.

Una situación que ejemplifica esta situación, la constituye la descripción del caso específico de Caleta Los Bronces, la cual se ubica a $35 \mathrm{~km}$ al sur-oeste del centro urbano de la comuna de Freirina, en la Provincia del Huasco, Tercera Región de Atacama. Chile. Presenta un clima desértico costero, y vías de difícil acceso (huellas) entre quebradas y cerros de la Cordillera de la Costa. Carece de servicios básicos: electricidad, agua potable y alcantarillado; e infraestructura portuaria (atracadero, muelle). Las viviendas (mediaguas) se emplazan en forma dispersa por el borde costero en una extensión mayor a $5 \mathrm{~km}$., ocupación irregular en terrenos de propiedad fiscal y propiedad privada. Sus habitantes (40 aprox.) se agrupan en un Sindicato de Trabajadores Independientes (20 socios aprox.) y a la vez en una Junta de Vecinos que les permite vincularse de mejor manera con diversas instituciones publicas. Actualmente cuentan con una sede equipada, radio VHF, mobiliario, TV y video VHS, equipo inversor eléctrico con placas solares y baterías, un vehículo camión $4 \times 4$ propiedad del Sindicato, y una embarcación con motor fuera de borda, para el cuidado y vigilancia del área de manejo. 
En Chile la extracción de recursos algales se inició en la década del'50 con especies de Chondrus y Gracilaria. A la fecha, la extracción está referida a unas 22 especies de macroalgas marinas con alta extracción de biomasa anual...Desgraciadamente de ellas solamente Gracilaria es objeto de cultivo y uso ordenado en concesiones particulares, pero ninguna otra especie es objeto de manejo ni de cultivo. (Alveal en Figueroa, 2005, p.453)

En las Caletas Rurales de las zonas costeras del norte chico de Chile, y en particular en Caleta Los Bronces, se ha propendido desde las Instituciones Públicas y/o Privadas que fomentan y asesoran técnicamente a este sector, a diversificar su actividad extractiva, de manera de acceder a recursos de alto valor comercial, como el molusco Loco, generando condiciones para su protección, conservación y manejo sustentable. Así mismo se ha incorporado, en forma pionera a nivel nacional, el manejo del recurso Macro-Alga. Es así como se ha logrado comercializar en forma asociativa los recursos cosechados, generando un impacto en la diversificación de sus ingresos, afectando sus estilos de vida, jerarquías, y comportamientos de consumo. La formalización de su actividad, ha propendido el tránsito de "recolectores" a "sustentadores" de la Pesca Artesanal, desde el individualismo en faenas hacia el trabajo participativo y grupal.

El Sindicato de algueros de Caleta Los Bronces, cuenta hace unos 5 años con un Área de Manejo, en la cual se realiza la administración y explotación sustentable de los recursos marinos autorizados de acuerdo a un plan de manejo, cosechando entre otros productos el molusco loco y las algas pardas. A la vez, en la Provincia del Huasco, se realiza el mayor desembarque de macroalgas en el país. (desembarque total año 2002, 47.782 toneladas), recurso que se procesa en plantas ubicadas en la zona y es demandado en Chile para la fabricación de agar y carragenano para el caso de algas rojas y para la obtención de ácido algínico o exportación molida para el caso de algas pardas. "La apertura de Chile a nuevos mercados extranjeros como Corea, China, Europa y especialmente Rusia, incrementa significativamente los requerimientos de hidrocoloides y con ello, demanda de mayor cantidad de algas en el país para la fabricación de estos mucílagos" (Alveal, en Figueroa, 2005, p.458).

A partir de este caso específico de experiencias de modernización se quiso identificar cambios surgidos a partir de la implementación de diversas políticas públicas, y metodológicamente, se asume una posición teórica desde la Teoría de Sistemas Constructivista, utilizando una metodología cualitativa, enfoque exploratoriodescriptivo, desde un enfoque socio-hermenéutico, cuyo propósito es la comprensión de los discursos sociales de sujetos reflexivos y sus consecuencias, a través de la observación de segundo orden.

\section{Cultura extractiva competitiva}

En esta sección se indica y describe las observaciones del discurso de los algueros de Caleta Los Bronces, observadores de primer orden de experiencias en torno a la recolección y comercialización de algas, sus faenas de pesca y vida cotidiana, en un contexto de cultura extractiva competitiva. A partir de estas descripciones e interpretaciones que responden al repertorio de medios disponibles en su comunidad, se profundiza en aquellos temas que caracterizan dicha forma cultural. 
Las características que definen los patrones básicos de una cultura extractiva corresponden al libre acceso a los recursos marinos, el individualismo en faenas y el intercambio individual. La lógica competitiva es la que orienta esta modalidad productiva, y las consecuencias que conlleva corresponden a la sobreexplotación de los recursos naturales, la planificación diaria e informalidad en las relaciones que establecen. La producción tradicional y de subsistencia junto a las técnicas artesanales extractivas empleadas, articulan y refuerzan la lógica competitiva.

Los factores que pueden tener un carácter causal, corresponden al período histórico de libre acceso a los recursos pesqueros, antes de la regulación sectorial impulsada a inicios de la década de los años noventa del siglo recién pasado. Así mismo, las comunicaciones referidas a hechos de individualismo en faenas y formas de comercialización individual de los recursos marinos extraídos y desde la lógica competitiva que la sustenta, posteriormente se analiza su influencia en las relaciones interpersonales de los algueros.

El modo de producción de subsistencia y las técnicas artesanales empleadas vinculadas al modo de vida tradicional propio de una cultura extractiva es lo que caracteriza a los pescadores artesanales en un contexto previo al impacto de la globalización económica y los programas modernizadores impulsados por el Estado, en los espacios locales.

Los factores que son consecuencia de la emergencia de las características descritas anteriormente y articulados por una lógica competitiva. Entre estas consecuencias se encuentran las experiencias de sobreexplotación de los recursos hidrobiológicos observadas por los algueros y las implicancias que ello acarrea en su relación con el entorno natural y social. Así mismo, se identifican las consecuencias en las expectativas de vida de los algueros, a partir de experiencias de trabajo de alto riesgo en el mar, que se traducen en una planificación diaria e informalidad en las relaciones productivas, comerciales e interpersonales, en la cual la acumulación de capital es un elemento desconocido.

Lo señalado en los párrafos anteriores, se aborda describiendo las principales características de la cultura extractiva competitiva, a partir de la observación de observaciones de los algueros de Caleta Los Bronces, el qué y cómo observan, es decir “... describir- registrar/inscribir-una cultura a partir de las categorías descriptivas de sus descriptores." (Arnold, M., en Osorio, F. 2004, p.19) ; y para finalizar el análisis mas adelante se intenta relevar lo que desde sus parcialidades los algueros no pueden ver, es decir algunas descripciones que dan cuenta de un proceso de cambio cultural, que promueve la idea de sustentabilidad, introducida por las estrategias de modernización.

Como antecedente complementario al desarrollo de los temas que caracterizan la cultura extractiva competitiva, se puede señalar que históricamente, la actividad pesquera artesanal ha significado una alternativa productiva y de subsistencia atractiva para la mano de obra desplazada de otras actividades productivas deprimidas como la pequeña minería artesanal (en aquellos períodos de bajos precios de los metales), la agricultura y otras labores presentes en las ciudades. El primer acercamiento laboral a esta actividad se realiza generalmente bajo la modalidad de "recolectores de orilla", mariscadores o algueros. Esta aproximación a la actividad pesquera artesanal introduce una modificación importante en los estilos de vida de las personas que la 
practican, dado que generalmente se desarrolla en territorios alejados de centros urbanos, de difícil acceso y en sectores carentes de servicios básicos, electricidad, agua potable, y otros. Por lo mismo, los "rucos", pequeñas viviendas fabricadas de piedras, ramas y material de desecho, se constituyen en hogares provisionales mientras se permanece en la playa realizando la actividad extractiva, que puede variar de algunas semanas a varios meses continuado. Esto mismo dificulta la permanencia de hijos menores de edad en estas condiciones, quienes generalmente asisten a establecimientos educacionales en los centros poblados mas cercanos, y viven en otros hogares junto a la madre, abuelos o algún otro adulto responsable de su cuidado.

La cultura extractiva del pescador artesanal establece una estrecha relación del hombre con su fuente de trabajo, el mar, a la vez que genera una incertidumbre que lo lleva a realizar una planificación a corto plazo, diaria, que atenta contra formas asociativas de trabajo (informalidad e individualismo en faenas).

Si en este sentido se analiza la normativa que regía al pescador hace 30 años o menos, se constata que prácticamente no existían requisitos legales para poder ejercer el oficio de pescador artesanal; solamente era necesario mostrar las capacidades propias que demanda el trabajo en el mar (FNSP, 1998, p.21).

Así mismo, en la forma tradicional la actividad del alguero es marcadamente individual, se trabaja en un "varadero" específico, cercano al "ruco" y la comercialización se hace en forma directa con el "intermediario", comerciante que cuenta con vehículo de carga mayor, y quien fija un precio por kilo de alga seca y a la vez provee de víveres y agua potable al alguero. Sin embargo, a pesar de la competencia generada por la recolección de alga, a la vez, el aislamiento en que se encuentran, genera ciertos rasgos de solidaridad con su comunidad, para brindarse protección mutua, acompañamiento, recreación, etc.

“Tradicionalmente las pesquerías chilenas estuvieron bajo un régimen de libre acceso, con una intervención mínima del estado, y con restricciones biológicas tales como la definición de vedas y tamaños mínimos de captura" (CONAMA, 1997, p.19).

A continuación se presenta un esquema de relaciones causales, con las principales características de una cultura extractiva competitiva del sector pesquero artesanal.

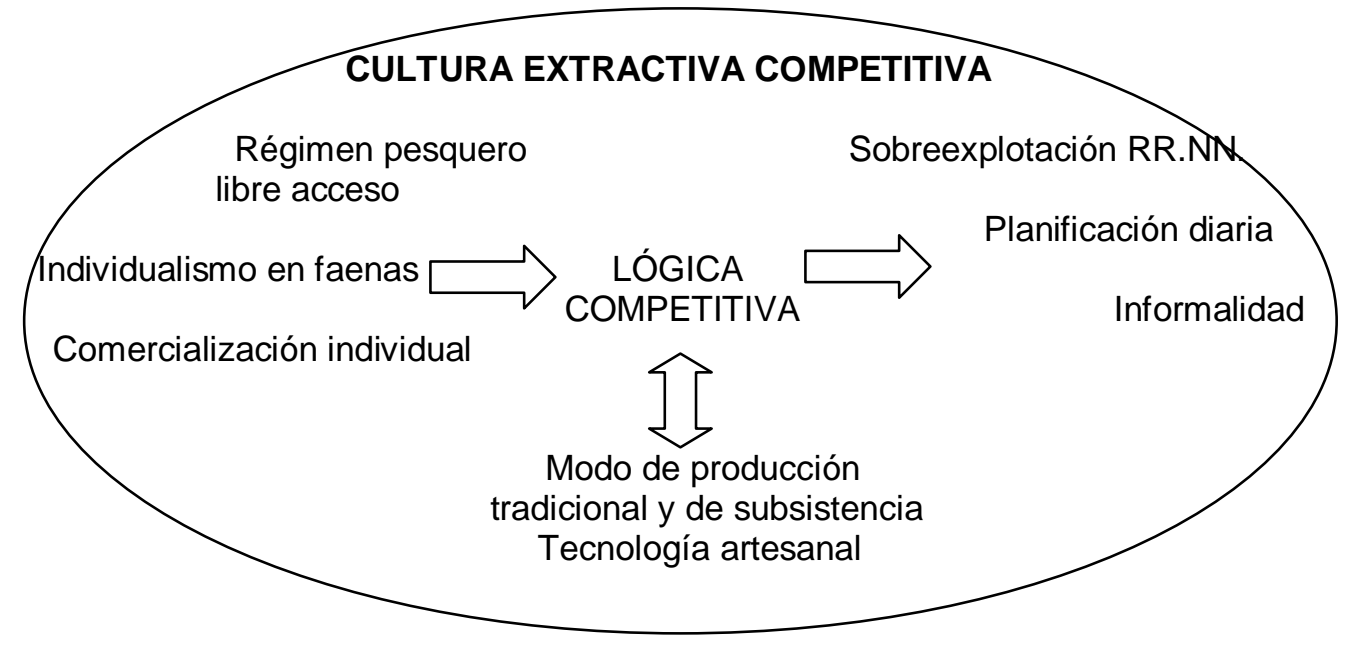

Revista Mad. $N^{\circ}$ 17, Septiembre de 2007. Departamento de Antropología. Universidad de Chile http://www.revistamad.uchile.cl/16/marin_06.pdf 
El libre acceso a los recursos, junto al individualismo en faenas y la comercialización individual se identifican como los patrones básicos que articulan la lógica competitiva de una cultura extractiva de los pescadores artesanales, y que son causantes de la sobreexplotación de los recursos marinos, de la planificación diaria e informalidad de las relaciones interpersonales y comerciales, lo cual redunda en dependencia del intermediario y bajos precios obtenidos en la venta del alga, por sobreoferta.

En el caso de Caleta Los Bronces, en un contexto de cultura extractiva competitiva, inicialmente los esfuerzos modernizadores impulsados por el Estado y que promueven la asociatividad se ven obstaculizados por formas de convivencia individualistas en las cuales la desconfianza en el otro genera conductas de resistencia al cambio cultural propuesto.

La regulación de la actividad pesquera artesanal, genera la consolidación de asentamientos costeros delimitados geográficamente a la cercanía de áreas de explotación autorizadas según un plan de manejo. Tal situación provoca cambios en el estilo de vida tradicional nómada y planificación diaria de los pescadores artesanales, surgiendo la privatización de los recursos marinos bentónicos entregados a la administración de un sindicato de pescadores en particular, promoviendo visiones a largo plazo y consolidando la permanencia en una determinada zona geográfica. La idea de asociatividad y sustentabilidad comienza a emerger.

En el siguiente apartado se caracteriza la cultura sustentable asociativa emergente del sector pesquero artesanal, identificando, describiendo y analizando los principales temas surgidos en torno a los discursos sostenidos por los algueros y entornos relevantes.

\section{Cultura sustentable asociativa}

El cuestionamiento a las tensiones surgidas en las relaciones entre modernidad y medio ambiente, llevan a Guimaraes, R. (2002) a proponer un nuevo estilo de desarrollo, ambientalmente sustentable en el acceso y uso de los recursos naturales y preservación de la biodiversidad; socialmente sustentable en la reducción de la pobreza y desigualdades; culturalmente sustentable en la conservación del sistema de valores, prácticas y símbolos de identidad; y políticamente sustentable al profundizar la democracia. Desde esta perspectiva de desarrollo, los objetivos económicos deben estar subordinados a las leyes de funcionamiento de los sistemas naturales, respeto a la dignidad humana y mejoría de la calidad de vida de las personas.

Desde la perspectiva del PNUD (1998):

La propuesta de un Desarrollo Humano Sustentable obliga a mirarnos mas allá de los indicadores macroeconómicos y considerar asimismo la subjetividad. Tomar al ser humano por la "razón de ser" del desarrollo implica tomar en cuenta sus opiniones e intereses, sus deseos y miedos. (p.46)

Concordante con lo anterior Figueroa (2002) señala que los ecosistemas marinos son un capital natural y fuente de valor social muy importante, y particularmente en Chile, 
los recursos marinos contribuyen al empleo, fuente de alimentación y de recreación, entre otros usos y aportes al desarrollo del país. La regulación pesquera impulsada en los últimos veinte años, promueve la idea de conservación de los recursos hidrobiológicos, sin descuidar el bienestar humano, en particular de los hombres de mar.

La Ley General de Pesca y Acuicultura (Ley 18.892, establecida por el Decreto Supremo 430, de 1991), "introdujo una serie de elementos ordenadores que han permitido controlar el incremento de la actividad pesquera sin afectar significativamente la sustentabilidad de los recursos hidrobiológicos" (CONAMA, 1997, p.20). La idea de conservación de los recursos marinos y su manejo sustentable, comienza a emerger y se materializa en las denominadas Áreas de Manejo y Explotación de Recursos Bentónicos (AMERBs), las cuales se han constituido en experiencias en que la autoridad asigna derechos comunitarios exclusivos de extracción sobre ciertos recursos, por un período determinado, a organizaciones de pescadores artesanales, a partir de un plan de manejo sustentable económica y ambientalmente.

Los factores que definen los patrones básicos de una cultura sustentable corresponden a la regulación de la actividad pesquera, el trabajo participativo y grupal y la comercialización asociativa. El atributo que orienta esta modalidad productiva, es la lógica asociativa, y las consecuencias que introduce corresponden a la conservación de los recursos naturales, la planificación a largo plazo y la formalidad en las relaciones que establecen. La producción moderna y la administración empresarial junto a la tecnología industrial, articulan y refuerzan la lógica asociativa.

Los factores que pueden tener un carácter causal, se corresponden con la regulación de la actividad pesquera artesanal, impulsada a partir del año 1991. De igual forma, las comunicaciones referidas a hechos de trabajo participativo y grupal, y las formas de comercialización asociativa de los recursos marinos extraídos, se constituyen en factores causales de la emergencia de una cultura sustentable asociativa. Articulan y refuerzan la lógica asociativa, el modo de producción empresarial y la utilización de tecnologías industriales empleadas vinculadas a un modo de vida moderno, en un contexto de globalización económica y de implementación de programas modernizadores impulsados por el Estado, en los espacios locales.

Aquellos factores que dan cuenta de las consecuencias del impacto de los factores descritos y articulados por una lógica asociativa, entre otros son: las experiencias de conservación de los recursos hidrobiológicos observadas por los algueros y las implicancias que ello acarrea en su relación con el entorno natural y social. Así mismo, se identifican las consecuencias en la planificación a largo plazo de la vida de los algueros, y la formalización de las relaciones productivas, comerciales e interpersonales, en la cual la organización es un factor determinante en la vinculación con la red institucional formal.

Con estos antecedentes, a continuación se presenta un nuevo esquema de relaciones causales con las principales características de una cultura sustentable asociativa emergente del sector pesquero artesanal. 


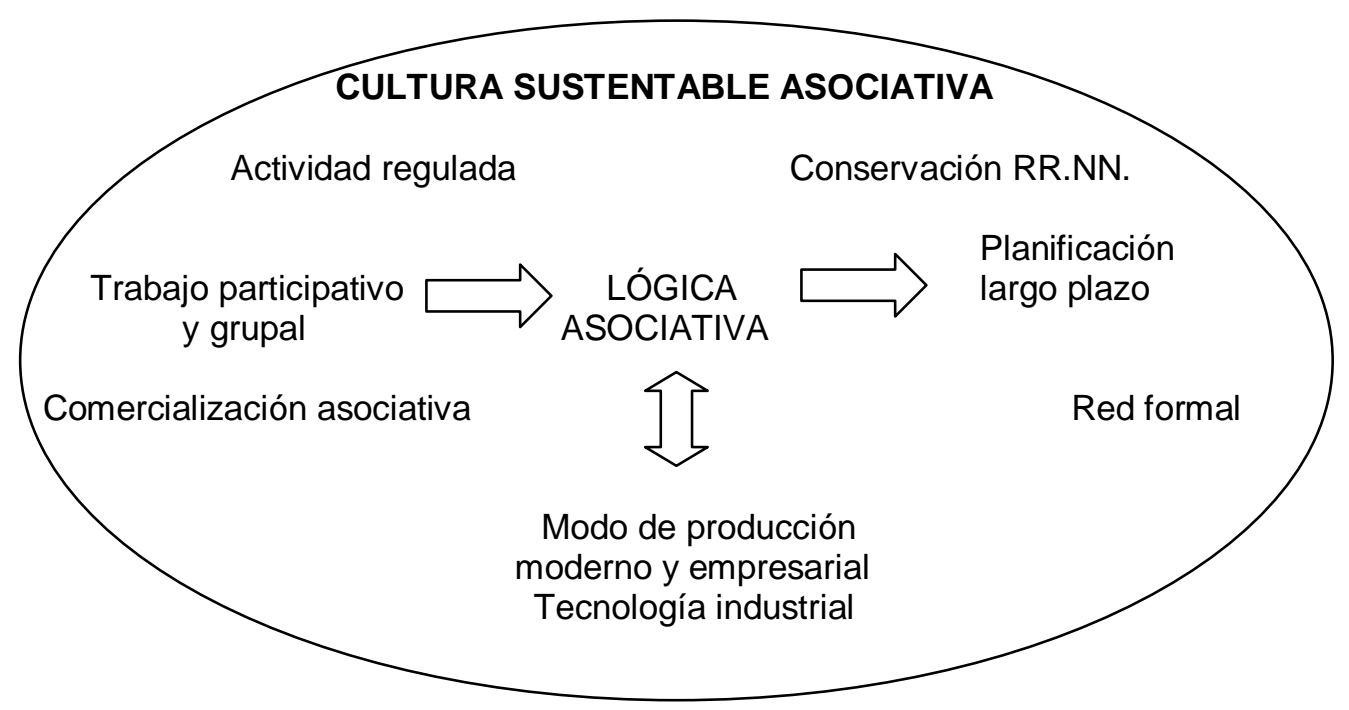

Esquema relaciones causales, cultura sustentable asociativa, elaboración propia (2007)

A modo de resumen se puede concluir que la lógica asociativa que orienta la construcción de una cultura de la sustentabilidad, permite incorporar las visiones y opiniones de los beneficiarios de los programas gubernamentales, a modo de garantizar la pertinencia y éxito de las intervenciones sociales de los programas modernizadores impulsados por el Estado, para insertarse en un mercado globalizado, aumentando su eficacia y eficiencia funcional.

A continuación, se presenta la reflexión a partir del encuentro o hibridación desequilibrada entre una cultura extractiva competitiva y una cultura sustentable asociativa, y se presentan las conclusiones finales, las cuales intentan relacionar los distintos temas analizados y su conexión con los modelos teóricos y objetivos propuestos en la investigación realizada.

\section{Conclusiones}

A modo de reflexión final y a manera de síntesis, en este apartado se plantea un modelo diferencia directriz (cultura extractiva competitiva/ cultura sustentable asociativa); un modelo de hibridación de prácticas sociales; y se abordan los conceptos relevantes: cultura, modernización e hibridación, que permiten delimitar teórica y metodológicamente los ámbitos de observación desde los cuales se orienta el proceso de recolección y análisis de información obtenida desde los discursos de los algueros y entornos relevantes, desde los cuales se plantean las conclusiones finales de este estudio.

\subsection{Conceptos relevantes}

\subsubsection{Modelo diferencia directriz}


En primer lugar, se presenta un modelo diferencia directriz en el cual esquemáticamente se presentan las culturas pesqueras que se entrecruzan y que se caracterizan de la siguiente forma:

\section{CULTURA EXTRACTI VA COMPETI TI VA}

Régimen pesquero de libre acceso

Individualismo en faenas

Informalidad

Sobreexplotación RR. NN.

Intercambio individual

Tecnología artesanal

Planificación diaria

Producción de subsistencia

Tradición

\section{CULTURA SUSTENTABLE ASOCI ATI VA}

Actividad regulada

Trabajo participativo y grupal

Red formal

Conservación RR. NN.

Comercialización asociativa

Tecnología industrial

Planificación a largo plazo

Administración empresarial

Modernización

Elaboración propia (2007)

A partir de este esquema diferencia directriz (cultura extractiva competitiva / cultura sustentable asociativa) se plantea la distinción que guía los ámbitos de observación de la teoría y especifica el centro del problema de investigación, que se plantea a continuación: Las exigencias de cambio cultural de los programas de modernización del subsector pesquero artesanal, su lógica y orientación, colisionan con ciertos aspectos de la sociedad tradicional expresada en la cultura extractiva de los pescadores artesanales, sus creencias, valores, relaciones sociales y modos de producción.

\subsubsection{Modelo de hibridación de prácticas sociales}

Así mismo, el esquema conceptual básico del problema planteado en este estudio, es el concepto de Prácticas Sociales Recurrentes planteado por Giddens y surgido al interior del paradigma hermenéutico, que intenta integrar la acción social percibida en un nivel sociocultural micro, y la estructura o los sistemas ubicados en un nivel de análisis macro. La tensión y tipos de resultados que se generan a partir de dicho encuentro, se presenta esquemáticamente de la siguiente forma:

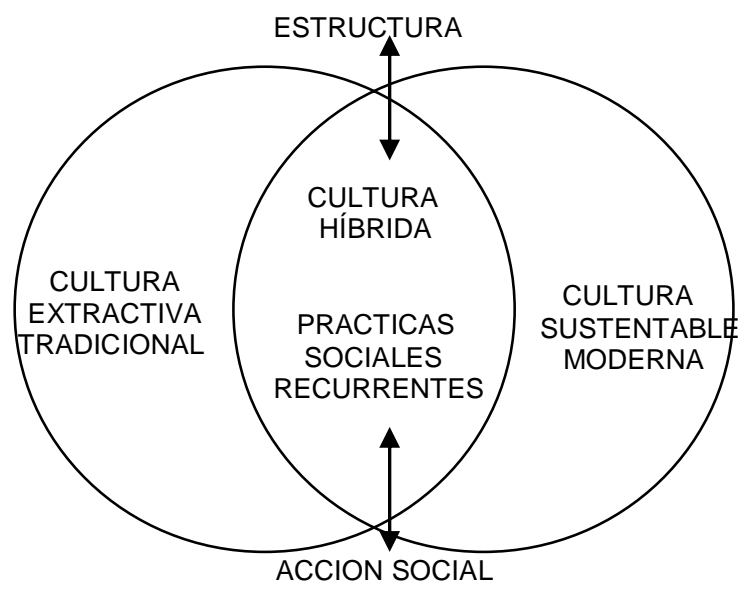

Elaboración propia (2005) según planteamientos de Giddens y García Canclini

Revista Mad. $N^{\circ}$ 17, Septiembre de 2007. Departamento de Antropología. Universidad de Chile 
En este modelo se observa la intersección y entrecruzamiento que se produce entre un nivel sociocultural micro (acción social) y sistemas sociales macro (estructura); y una cultura pesquera extractiva tradicional y una cultura pesquera sustentable que promueve la modernidad. Las prácticas sociales recurrentes, se ubican al centro de este modelo en el cual los actores (pescadores artesanales) se constituyen en los principales agentes de cambio, y a través de la práctica se produce la conciencia y la estructura.

\subsubsection{Cultura, modernización, hibridación}

Se plantea un conjunto de conceptos interrelacionados que permiten generar una explicación sobre el fenómeno que en este estudio se ha descrito en relación a las exigencias de cambio cultural de los programas de modernización del sector pesquero artesanal, su lógica y orientación, que colisionan con ciertos aspectos de la sociedad tradicional expresada en la cultura extractiva de los pecadores artesanales.

Los conceptos y categorías relevantes que guían esta investigación son:

- Cultura

- Modernización

- Hibridación

Estos conceptos se relacionan entre sí desde la tensión que surge del entrecruzamiento entre una cultura tradicional y una modernización acelerada en la cual se observan procesos de hibridación desigual que responden a lógicas distintas de orientación del proceso de cambio socio productivo impulsado por el Estado por medio de la política social, y el mercado por la preponderancia de su lógica instrumental medio-fines; y las necesidades e intereses locales que en muchas ocasiones se contraponen.

El concepto cultura operativamente se utiliza desde una perspectiva cognitiva delimitando la observación a pautas, creencias y reglas o costumbres de los algueros en sus faenas de pesca y relaciones cotidianas, actividades individuales, grupales y organizacionales y en retrospectiva y comparativamente en relación a modos de vida, acontecimientos y prácticas sociales vivenciadas en un período de 15 años aprox. desde la redemocratización del país, y continuidad del proceso modernizador y de apertura económica, reforma del Estado, ejemplificado en nuevas medidas reguladoras impulsadas con la promulgación de la Ley General de Pesca y Acuicultura, (período iniciado el año 1990 - aprox.)

Entendiendo por cultura la concepción que desarrolló Goodenough, según la cual “la cultura está situada en el entendimiento y en el corazón de los hombres". (Geertz, 1973 (1986): p.4). Esta escuela de pensamiento (antropología cognitiva) sostiene que la cultura está compuesta de estructuras psicológicas mediante las cuales los individuos o grupos guían su conducta. La "cultura de una sociedad... consiste en lo que uno debe conocer o creer a fin de obrar de una manera aceptable para sus miembros" (Geertz, 1973 (1986): p.5).

Complementariamente, y en relación al caso de estudio, se destaca la definición de Recasens (2003), quien señala que los pecadores artesanales viven su cultura como 
código mapa y ruta, intermediados por la experiencia. Y Humberto Maturana "sostiene que una cultura es una red cerrada de conversaciones y que el cambio cultural ocurre cuando se produce un cambio de conversaciones en esa red; cambio que surge, se sostiene y mantiene en el emocionar de los miembros de la comunidad" (Ruiz, 2002: p.6)

Operacionalmente, y como herramienta de observación se entenderá el concepto de cultura desde una perspectiva cognitiva según la concepción desarrollada por Arnold, M., (2002), que describe los siguientes atributos de la cultura de las cuasiorganizaciones (cultura organizacional): etnocogniciones (visión problematizada); etnoconocimientos (informaciones, comunicación comunitaria); y etnosociologías (acciones, escala personal).

Las etnocogniciones, son entendidas como sus formas de observación: ¿cómo se observan y organizan entornos?. Pautas que toman la forma de palabras;

Los etnoconocimientos, sus distinciones: ¿cómo son las cosas para los miembros de una organización?. Creencias compartidas por el grupo; y

Las etnosociologías, sus modalidades de organización: ¿cómo se organizan las relaciones sociales?. Reglas sociales, rutinas y costumbres.

Así mismo el concepto de modernización se emplea para caracterizar el proceso de transformaciones productivas y sociales impulsado por el Estado en un contexto de globalización económica y cultural; y en este estudio se analiza desde posiciones críticas al modelo económico hegemónico capitalista en su expresión neoliberal, que colisiona con formas tradicionales de trabajo y organización e identidades locales resistentes a su lógica modernizadora y su ritmo acelerado. Según Solé (1998), la modernización no será un proceso lineal (de una sociedad "campesina" a otra "moderna"), si no que tendrá tantos puntos de partida como tipos de sociedades tradicionales existan. Para los antropólogos sociales, la modernización es considerada un proceso endógeno, en el cual se considera la sociedad como estructura o sistema social dentro de un contexto atemporal (económico, político, legal, etc.). La integración de estas subestructuras constituye la necesidad principal de la estructura social y la causa y función de las instituciones sociales. Así, modernización equivale a cambio estructural. Por el contrario, los primeros antropólogos culturales (Malinowski), conciben la sociedad como un cuerpo humano, en el cual las partes cumplen la función de mantener la totalidad. La sociedad se considera como una cultura situada en un contexto histórico determinado. Desde esta perspectiva se supone que las sociedades pueden adaptar rasgos culturales de otras sociedades en lugar de auto desarrollarlos. El cambio social comenzará por el contacto cultural (aculturación). "Según la visión de los antropólogos culturales, el proceso global de contacto cultural podría considerarse como equivalente a la modernización, como un tipo de proceso exógeno" (Solé, 1998, p. 5). De acuerdo a Solé, ambas visiones (estructural y cultural) no consiguen explicar los fenómenos que constituyen la modernización.

Al revisar estudios nacionales sobre el impacto de la modernización en la sociedad chilena, el PNUD (1996) plantea que los cambios registrados en los inicios de la década del noventa del siglo recién pasado, afectan especialmente la vida cotidiana de la gente y su sociabilidad, con sus tejidos familiares y comunitarios, sus valores e 
identidades. La tensión entre modernización y subjetividad genera inseguridad al no considerar lo suficiente la dimensión subjetiva del desarrollo.

De igual forma, el informe del PNUD, 1998 intenta comprender el sentido y orientación de la modernización en marcha y su impacto en la vida cotidiana de la gente y su sociabilidad. A la vez señala que se observa un malestar posiblemente derivado de que los mecanismos de seguridad que ofrece el actual "modelo de modernización" resultan insuficientes o ineficientes. A pesar de los éxitos obtenidos, la seguridad humana en Chile no tendría un nivel satisfactorio y se encontraría distribuida de manera desigual.

A modo de síntesis se utiliza el concepto de hibridación para describir las adaptaciones, cambios y consecuencias en la dimensión cultural de la globalización, a nivel local. Se trata de observar por medio de los discursos de los algueros y observación panorámica no participante, elementos y artefactos culturales (técnicas, tecnología, conocimientos, modos de organización, etc.) que dan cuenta de la tensión o hibridación cultural de la lógica competitiva y la orientación asociativa del enfoque modernizador.

Para interpretar las mezclas que se generan a partir del tránsito de una cultura extractiva competitiva a una cultura sustentable asociativa, recurrimos al concepto de hibridación elaborado por Néstor García Canclini (2003), quien entiende este concepto como los "procesos socioculturales en los que estructuras o prácticas discretas, que existían en forma separada, se combinan para generar nuevas estructuras, objetos y prácticas" (p. 2). Además este autor señala que "a menudo la hibridación surge de la creatividad individual y colectiva. No solo en las artes, si no en la vida cotidiana y en el desarrollo tecnológico. Se busca reconvertir un patrimonio (una fábrica, una capacitación profesional, un conjunto de saberes y técnicas) para reinsertarlo en nuevas condiciones de producción y mercado." (García Canclini, N., en Revista Transcultural de Música, 2003, p. 4). El autor propone para darle poder explicativo al concepto hibridación: "estudiar los procesos de hibridación situándolos en relaciones estructurales de causalidad. Y darle capacidad hermenéutica: volverlo útil para interpretar las relaciones de sentido que se reconstruyen en las mezclas" (García Canclini, N. 2003, en Revista Transcultural de Música, p.5)

En un contexto de globalización, ésta acentúa tendencias de la modernidad al crear mercados mundiales de bienes, mensajes y migrantes. Las interacciones surgidas han debilitado la autonomía de las tradiciones locales, y propician mas formas de hibridación productiva, comercial, comunicacional y en los estilos de consumo que en el pasado. La globalización integra y mezcla, a la vez segrega y genera nuevas desigualdades. "Un mundo en creciente movimiento de hibridación requiere ser pensado no como un conjunto de unidades compactas, homogéneas y radicalmente distintas sino como intersecciones, transiciones y transacciones." (García Canclini, N., en Revista Transcultural de Música , 2003, p.10).

\subsection{Conclusiones}

En el siguiente apartado se presentan las conclusiones y reflexiones finales a partir del proceso de investigación realizado, y en particular de los resultados del análisis de información obtenida desde los discursos de los algueros de Caleta Los Bronces y entornos relevantes, en relación al proceso de cambio sociocultural vivenciado desde 
una cultura pesquera extractiva tradicional a una cultura pesquera sustentable emergente, identificada con la Modernidad.

La difusión de las conclusiones de esta investigación posibilitaría al sindicato de algueros y otras organizaciones de pescadores artesanales e instituciones públicas y privadas vinculadas al fomento productivo de este sector, orientar futuras decisiones de inversión, incorporando el componente sociocultural en su análisis.

A continuación se presentan las principales conclusiones elaboradas.

En primer lugar, hay que señalar que la diversidad de temas en los cuales se clasificó los contenidos de los discursos obtenidos en las entrevistas realizadas, se corresponde con el modelo diferencia directriz elaborado que da cuenta de las principales características de una cultura extractiva competitiva y otra sustentable asociativa. (Modelo elaboración propia ,2007)

Los resultados de la investigación indican que los programas modernizadores impulsados por el Estado, y su lógica del mercado globalizado, se incorporan en la trama de significados de la cultura local y prácticas sociales de los algueros, desde la dimensión económica, ejemplificado en el establecimiento de contratos formales de compra-venta con los comerciantes intermediarios, y finalmente en la obtención de mejores precios. Este aumento en los ingresos conlleva el acceso a bienes durables y equipamiento orientado al mejoramiento de las condiciones de vida en aspectos relacionados con necesidades de protección, vivienda, transporte y uso del tiempo libre. Lo señalado anteriormente contribuye a reducir las relaciones de dependencia hacia los comerciantes intermediarios.

Un aspecto importante que se menciona como consecuencia de la formalización y la incorporación de la dimensión sustentabilidad en las faenas de recolección, corresponde a los cambios en la dimensión temporal, lo cual se ejemplifica en el establecimiento de un horario de trabajo limitado y consensuado, como forma de adaptación alcanzada a partir del establecimiento de relaciones colaborativas y acuerdos derivados del trabajo grupal. Dicho cambio de prácticas se vincula con el tema de la comercialización asociativa y conservación de los recursos naturales, y da cuenta del cambio de una conciencia marcadamente individualista y una estructura social que denominamos cultura extractiva competitiva, desde la cual se transita hacia formas de conciencia colaborativas y sistemas sociales macro que promueven una sustentabilidad socioeconómica, cultural y ambiental. Algunos de sus efectos son mayor disponibilidad de tiempo para el ocio y la recreación, mayor participación comunitaria, acceso a capacitación, entre otros.

La globalización y modernidad han llegado a los diversos espacios rurales chilenos provocando importantes transformaciones en sus sistemas de producción, en las condiciones medioambientales, en las redes sociales, en los estilos de vida de las diversas poblaciones y en sus culturas locales. La vida cotidiana de las localidades rurales ha cambiado significativamente (Hernández, R. \& Thomas, C., 2001). Desde esta perspectiva, lo que interesa visibilizar son las formas que adopta la sociabilidad en un contexto de cambio cultural. La lógica instrumental medio-fines se extiende a diversos espacios locales promoviendo relaciones competitivas entre sus miembros. En el caso de Caleta Los Bronces, en un contexto de cultura extractiva tradicional, 
inicialmente los esfuerzos modernizadores impulsados por el Estado y que promueven la asociatividad se ven obstaculizados por formas de convivencia individualistas en las cuales la desconfianza en el otro genera conductas de resistencia al cambio cultural propuesto.

Dichas formas de convivencia individualistas se pueden comprender desde el concepto de Prácticas Sociales Recurrentes planteado por Giddens y surgido al interior del paradigma hermenéutico, que intenta integrar la acción social percibida en un nivel sociocultural micro, y la estructura o los sistemas ubicados en un nivel de análisis macro. En su teoría Giddens se centraliza en las prácticas sociales, de modo que su objetivo es establecer una relación entre acción y estructura, donde ambas no pueden concebirse por separado. Según Flores, R., (en Osorio, 2004), Giddens en su reflexión en torno al concepto de acción, le asigna un lugar central al agente, dado que éste tendría capacidad de realizar cambios en el mundo social. La acción posee el poder de transformar situaciones, a través del actor.

A partir de este agente de cambio, se observa que la forma que adopta el trabajo grupal es la de una organización sindical, es decir una Cuasi-Organización, usando la terminología acuñada por Arnold, M. (2002), y su origen proviene de una imputación autoproducida (entorno interno) por la comunidad de algueros de Caleta Los Bronces, y por el surgimiento de un liderazgo natural que conduce el proceso autoorganizacional, condicionado por factores geográficos y climatológicos que crean la necesidad de apoyo mutuo para la resolución de un problema específico que es el aislamiento producido por un temporal de lluvia. A partir del discurso de un actor del entorno relevante, como es el Servicio Nacional de Pesca, se señala un origen sindical condicionado por el sistema económico, en particular factores de comercialización como una necesidad interna de unificar precios y aumentar sus ingresos. Desde la perspectiva Sistémico Constructivista, tal situación opera a partir del medio de comunicación simbólicamente generalizado del dinero. Así mismo, se identifica un origen organizacional derivado de impulsos asociativos de programas del Estado (entorno externo) que promueven la conservación de los recursos hidrobiológicos, y la implementación de medidas de administración y manejo sustentable de recursos en peligro de extinción.

La regulación de la actividad pesquera artesanal, genera la consolidación de asentamientos costeros delimitados geográficamente a la cercanía de áreas de explotación autorizadas según un plan de manejo. Tal situación provoca cambios en el estilo de vida tradicional nómade y planificación diaria de los pescadores artesanales, surgiendo la privatización de los recursos marinos bentónicos entregados a la administración de un sindicato de pescadores en particular, promoviendo visiones a largo plazo y consolidando la permanencia en una determinada zona geográfica, promoviendo la idea asociativa y la construcción de una comunidad de algueros identificada con Caleta Los Bronces.

La formalización de la actividad productiva (sistema económico y jurídico) de los algueros, opera cambios en el entorno (sistema psíquico y ambiental) que se traduce en una mayor predisposición a actuar desde una lógica emprendedora, conservacionista y colaborativa. 
A nivel de relaciones interpersonales, actualmente los conflictos se canalizan por la institucionalidad del sindicato, por lo que disputas personales se resuelven sin uso de la violencia física y verbal, situaciones que son castigadas por el sistema de disciplina instaurado por la organización. La convivencia ha mejorado, y a partir de la evolución experimentada en las formas de sociabilidad, se ha constituido una identidad común, una comunidad de algueros, que desde motivaciones económicas ha logrado establecer una red de interconexión y comunicación que trasciende a otras dimensiones de la vida cotidiana. Esta situación contradice en parte los resultados del informe del PNUD (1998) que establece cierta ineficiencia e ineficacia en los mecanismos de seguridad humana del actual modelo de modernización.

Como consecuencia de la organización, los algueros han logrado visibilidad social y que sus demandas sean atendidas por las autoridades locales, y de esta forma acceder a diversas prestaciones sociales, asistenciales y de fomento productivo.

En relación al tema de sobreexplotación de los recursos marinos, en los discursos sostenidos por los algueros se observa una externalización de la responsabilidad del daño ambiental, haciendo referencias a causas del entorno, naturales principalmente. Desde las comunicaciones registradas en el entorno experto, se observa referencias a causas autogeneradas por la sociedad, en el sistema económico, por la práctica extractiva de algas adosadas a la roca, la técnica del "barreteo".

En esta perspectiva, los trabajadores de mar se constituyen en los principales agentes protectores de su entorno, al ser ellos quienes permanecen en el lugar y requieren que los recursos se renueven biológicamente y mantener el equilibrio ecosistémico, para garantizar la presencia en el área de la biodiversidad marina para próximas cosechas y también la existencia para generaciones futuras. Sin embargo, la informalidad de algunas personas ajenas al Sindicato, recolectores oportunistas de temporada, que ejercen informalmente la actividad de recolección de algas, atentan contra los esfuerzos conservacionistas impulsados por la institucionalidad pesquera y los algueros formalizados. Por lo anterior se requiere una mayor fiscalización de parte de los organismos públicos.

En torno al tema de la comercialización se puede concluir que, los intermediarios al preferir el volumen de productos que exige el mercado, antes que la oferta dispersa, posibilita la asociatividad, y el establecimiento de contratos de compraventa, lo cual constituye una garantía de estabilidad a mediano plazo, permitiendo con ello negociar precios, lo cual redunda en un cambio cultural importante en relación a las proyecciones de ingreso futuras, permitiendo con ello planificar gastos e inversiones a mediano y largo plazo, consolidando la sustentabilidad de la actividad y la permanencia en la Caleta.

Respecto a la tecnología artesanal tradicional utilizada en la faenas de recolección de algas, se puede mencionar que el uso de la barreta o champeo constituye la principal técnica de daño ambiental del borde costero. Sin embargo, el varado de alga sigue siendo la principal fuente de volumen del recurso alga extraído, situación en la cual se combina el trabajo manual con rústicas tecnologías usadas para recolectar el alga flotante ubicada a mayor distancia de la orilla. El gancho, la araña, son algunas de las herramientas utilizadas. 
Junto a la emergencia de la modernización se introducen innovaciones tecnológicas que promueven un desarrollo productivo mas acelerado de la Caleta. La lógica de eficiencia, se incorpora en las prácticas productivas de los algueros en la explotación del área de manejo, por lo que introducen nuevos elementos tecnológicos para garantizar resultados óptimos en las cosechas y diversifican su actividad extractiva, desarrollando la pesca y el buceo, y de esta manera acceden a recursos que tradicionalmente no eran explotados por ellos, y en definitiva obtener mayores ganancias. Nuevas formas de hibridación, como la práctica del "barreteo" del alga se intersectan con productos de las tecnologías avanzadas (trajes y botas de goma) para generar acciones productivas con mayores grados de seguridad para la salud de los algueros.

La organización racionalizada de su producción y comercialización, los libera de su tradicional visión de corto plazo, ligada a una cultura extractiva, y un lugar determinado, la Caleta y sus actores presentes. Siguiendo a Giddens, es un ejemplo de los mecanismos de desanclaje, a través de la expansión de los mercados monetarios asociados a la modernidad. Se puede concluir que bajo una forma de vida tradicional, el aislamiento geográfico en un contexto de cultura extractiva competitiva, conlleva conductas individualistas y cierto grado de retraimiento emocional que dificulta la interacción con otros actores del entorno. Pero al mismo tiempo, las necesidades gatillan relaciones internas colaborativas entre los miembros de una misma comunidad. En la actualidad, los rucos, se presentan como vestigios culturales de un modo de vida nómada, y se han adaptado como bodegas o corrales de animales, dando cuenta del mejoramiento en la calidad de vida de los algueros. Así mismo, el mejoramiento de las condiciones de vivienda u otras dimensiones de la vida cotidiana, hace que los algueros aumenten su autoestima y se preocupen de aspectos como la apariencia física.

Finalmente, se concluye que la incorporación a redes globales de intercambio económico, conlleva cambios culturales importantes como la adaptación de prácticas productivas a mercados internacionales localizados a grandes distancias.

\subsection{Consideraciones finales}

Se puede afirmar que se ha dado cumplimiento al objetivo de identificar y analizar los contenidos del discurso de los algueros de Caleta Los Bronces referido a las adaptaciones, cambios y consecuencias de la modernización en la dimensión cultural del sector pesquero artesanal.

Por otra parte, el enfoque y conceptos relevantes, cultura, modernización, e hibridación que delimitan teórica y metodológicamente los ámbitos de observación desde los cuales se orienta el proceso de recolección y análisis de información obtenida desde los discursos de los algueros y entornos relevantes, han permitido sostener un modelo de elaboración propia que establece la caracterización de la diferencia directriz: cultura extractiva competitiva/ cultura sustentable asociativa; como así mismo, la propuesta del modelo de hibridación de prácticas sociales. Tales esquemas conceptuales, pueden ser aplicados en otros contextos espacio-temporales, para evaluar su utilidad como referentes de análisis. 
Respecto al aporte de este estudio a la disciplina antropológica y a las teorías del desarrollo, particularmente es interesante para la Antropología poder estudiar los efectos de la dimensión cultural del modelo globalizador, y a partir de los resultados y conclusiones de esta investigación, orientar futuras decisiones de inversión productiva en el sector pesquero artesanal, incorporando el componente sociocultural en su análisis, para garantizar mayores grados de pertinencia y eficiencia en el gasto social del Estado. Los aportes específicos para los algueros de Caleta Los Bronces, al identificar los contenidos de las comunicaciones en torno a la experiencia de modernización, se refieren a:

- Valoración de la biodiversidad marina y uso sustentable

- Independencia de intermediarios

- Construcción de identidad comunitaria

- Proyección temporal

En materia de estudios vinculados al desarrollo productivo local, y en particular de la actividad pesquera artesanal, esta investigación es novedosa al utilizar una metodología cualitativa (enfoque exploratorio-descriptivo), y un enfoque teórico metodológico socio-hermenéutico, cuyo propósito es la comprensión de los discursos sociales de sujetos reflexivos y sus consecuencias, a través de la observación de segundo orden, asumiendo una posición teórica desde la Teoría de Sistemas Constructivista.

Las limitaciones y alcances de este estudio se vinculan a identificar las consecuencias de la globalización en la dimensión cultural del sector pesquero artesanal. Las limitantes metodológicas se relacionan a la utilización de la técnica de entrevista abierta basada en guión de temas, que por factores de tiempo y acceso no fue posible profundizar en otros aspectos que fueron surgiendo en el desarrollo de las entrevistas, y complementación con otras fuentes de información y contexto. Así mismo, el análisis de la información recogida se limita al contenido de las entrevistas realizadas, sin plantear un análisis formal de la información obtenida de la observación panorámica no-participante, es decir, notas de campo y/o fotografías. Por último, la particularidad del modo de vida de los algueros, y la muestra estructural intencional, dificulta generalizar los resultados alcanzados a otros contextos locales. Las limitantes teóricas del estudio se vinculan a un marco conceptual poco desarrollado en cuanto a los modelos de desarrollo en juego, la modernización, el discurso del posdesarrollo, etc., y relación poco clara entre un proceso específico y dinámicas nacionales y globales. Así mismo falta ejemplificar y analizar en mayor profundidad, tensiones, hibridaciones y críticas sobre el proceso de modernización impulsado.

A partir del carácter exploratorio y descriptivo de este estudio, se plantean sugerencias de nuevas líneas de investigación. Explorar elementos de contexto (regional) y análisis de la estructura, que pudieran dar cuenta de otros procesos que influyen en el modelo extractivo construido, y que podría reflejar ciertos matices. Se hace necesario conectar el análisis de los actores con el análisis de la estructura con mayor profundidad. Así mismo, sería interesante, a partir de las entrevistas y para enriquecer el análisis, incorporar un análisis generacional: visión de los jóvenes comparada con los viejos. Cuántos cambios observan, cómo los enfrentan, los procesos de hibridación en cada uno, etc. De igual forma, incorporar el análisis desde la perspectiva de género, cambios en el trabajo en mujeres y hombres, etc. Se propone el desarrollo de 
investigaciones complementarias en términos disciplinarios $y$ de enfoques metodológicos distintos, que puedan profundizar en la evaluación técnico-económica de las áreas de manejo, incorporando el componente sociocultural en su análisis, tales como la variable educacional y situación socioeconómica de las familias de los algueros, dimensión que puede influir en el desarrollo de practicas extractivas sobreexplotadoras, con el objeto de aumentar los ingresos a partir de la comercialización de un mayor volumen de algas. Es decir, incorporar la variable humana en el estudio sobre la velocidad de recuperación del recurso. Por otro lado, se sugiere realizar investigaciones (biotecnología marina) en el borde costero chileno, ligadas al potencial uso de las macro-algas en la elaboración de biocombustibles, como alternativa sustentable a los combustibles de origen fósil (contaminantes), y como recurso estratégico de seguridad nacional que garantice mayores grados de autonomía y diversificación energética en el país. Los biocombustibles obtenidos de las algas, se constituyen como una alternativa económicamente viable a los obtenidos de plantas terrestres, para producir energía, tecnología patentada por empresa Israelí Seambiotic Ltd. (Aquahoy, 2007).

A modo de reflexión final, y en concordancia con la posición teórica adoptada en este estudio, los conocimientos que interesan son resultado de operaciones dependientes de las perspectivas y medios que poseen sus observadores. La investigación cualitativa opera con datos que son discursos, producidos desde los sujetos en situación de comunicación sobre el objeto de estudio. El lenguaje se constituye en instrumento y objeto de estudio. La difusión de las conclusiones de esta investigación aplicada, pretende contribuir al conocimiento del sector pesquero artesanal, y se plantea como un elemento orientador en su desarrollo, promovido por una diversidad de actores y prácticas sociales. $\mathbf{R M}$

\section{Bibliografía}

ALVARADO, M. (2001-2002). Mutaciones en el Discurso Antropológico Contemporáneo. Revista Chilena de Antropología, N 16, pp. 31-54. Departamento de Antropología, Facultad de Ciencias Sociales, Universidad de Chile.

AQUAHOY. (2007). El uso de las algas para la producción de biocombustibles. Recuperado el 30 de abril de 2007, de http://www.aquahoy.com

AQUAHOY. (2007). I srael: Patentan el uso de las algas marinas para producir energía. Recuperado el 30 de abril de 2007, de http://www.aquahoy.com

ARNOLD, M. (2003). Fundamentos del Constructivismo Sociopoiético. Cinta de Moebio No.18. Diciembre 2003. Facultad de Ciencias Sociales. Universidad de Chile, Recuperado el 19 de mayo de 2004, de http://www. moebio.uchile.cl/18/frames05. htm

ARNOLD, M., (2002). Modelos Culturales en Organizaciones Sociales Participacionales. La Cultura organizacional Comunitaria. Programa de Investigación y Formación para Organizaciones Asociativas y Cooperativas PROCOOP. Colección de Ciencias Sociales. Universidad de Chile. Bravo y Allende Editores. Chile.

ARNOLD, M. (1997) Antropologia social aplicada en organizaciones económicas y 
participacionales. Publicada en la Revista Chilena de Antropología. Recuperado el 30 de noviembre de 2005, de http://www.bibliotecadigital.cl

ARNOLD, M \& OSORIO, F. (1998). Introducción a los conceptos básicos de la Teoría General de Sistemas. Cinta de Moebio, $N^{\circ} 3$, Revista Electrónica de Epistemología de las Ciencias Sociales, Facultad de Ciencias Sociales. Universidad de Chile.

Recuperado el 19 de mayo de 2004, de

http://www.moebio.uchile.cl/18/frames05.htm

BRUNNER, J., (1990). Cambio Social y Democracia. Opinión. Estudios Públicos. Versión revisada de la ponencia del autor en seminario "Chile: la Izquierda en Transición", organizado por los centros VECTOR y AVANCE, que se efectuara en Santiago de Chile entre los días 3 y 5 de mayo de 1990, pp. 239-247.

CHANADY, A. (1997). La hibridez como significación imaginaria. Prepared for delivery at the 1997 meeting of the Latin American Studies Association, Continental Plaza Hotel, Guadalajara, Mexico, April 17-19, 1997.

Recuperado el 2 de noviembre de 2005, de http://136.142.158.105/LASA97/chanady.pdf

CONAMA, (1997). Gestión Ambiental del Gobierno de Chile. Borregard, N., \& Butelmann, A. Editores. Santiago de Chile, Primera Edición.

CONTRERAS, D. (1996). Pobreza y Desigualdad en Chile: 1987-1992. Discurso, metodología y evidencia empírica. Estudios Públicos, 64 (primavera 1996)

DE LAIRE, F. (2002) En Revista Perspectivas (Departamento de Ingeniería Industrial, Universidad de Chile), vol. 6, № 1, 2002 (pp. 141-158)

Recuperado el 30 de abril de 2005, de http://www. dii.uchile.cl/ revista/ArticulosVol6-N1/07-De\%20Laire.pdf

FIGUEROA, E. (editor), (2005). Biodiversidad Marina: Valorización, Usos y Perspectivas ¿Hacia dónde va Chile?. Programa Interdisciplinario de Estudios en Biodiversidad (PIEB) Universidad de Chile. Editorial Universitaria S.A. Primera edición. Santiago de Chile.

FRENCH-DAVIS, R., (1999). Entre el neoliberalismo y el crecimiento con equidad. Tres décadas de política económica en Chile. Dolmen Ediciones S.A. 1999, Santiago, pp. 2793.

FUND. NAC. PARA LA SUPERACIÓN DE LA POBREZA, (1998) Profesionales Servicio País 1997, Sector Pesca Artesanal, Diagnóstico y Propuestas, Visión del Sector Pesquero Artesanal, Bases de una Propuesta para su Desarrollo, Serie de Documentos $\mathrm{N}^{\circ} 2$, Tomo I, pp. 68.

GARCÍA CANCLINI, N. (2003). Revista Transcultural de Música 7. Noticias recientes sobre la hibridación.

Recuperado el 5 de diciembre de 2005, de

http://www. sibertrans.com/trans/trans7/canclini.htm 
GARCÍA CANCLINI, N. (1993). Una modernización que atrasa. La cultura bajo la regresión neoconservadora. Casa de las Américas, La Habana, octubre-diciembre de 1993, pp. 3-13. En fichas bibliográficas. Interculturalidad. Cuadernos de Investigación Bibliográfica.

Recuperado el 2 de noviembre de 2005, de http://latinculture.com/cdrom/fichasbibliograficas/271-277.htm

GARCÍ A CANCLINI, N., (1989). Culturas Híbridas. Estrategias para Entrar y Salir de la Modernidad. Grijalbo, México.

GEERTZ, C., (1973). Descripción Densa: Hacia una Teoría Interpretativa de la Cultura. La interpretación de las Culturas. Barcelona: Editorial Gedisa.

GIDDENS, A., (1999). Consecuencias de la Modernidad. Versión de Ana Lizón Ramón. Alianza Editorial. Primera edición en “Ensayo": 1999, Madrid, España.

GOBIERNO DE CHILE, SERNAPESCA, (2005). Organizaciones de pescadores de las comunas de Freirina y Huasco mejoran la comercialización de sus algas. El Faro. Boletín pesquero artesanal. Departamento de pesca artesanal del Servicio Nacional de Pesca. Año 4, no 12, junio 2005, pp. 8.

GUIMARAES, R., (2002). La ética de la sustentabilidad y la formulación de políticas de desarrollo. Ecología política, naturaleza sociedad y utopía, pp.53-82.

HERNÁNDEZ, R., \& THOMAS, C. (2001). Globalización y Educación Rural en Chile: Sus Efectos en el Proceso Educativo desde un Análisis Sistémico.

Recuperado el 15 de septiembre de 2005, de http://rehue.csociales.uchile.cl/antropologia/congreso/s1411.html.

LARRAÍ N, J. (1997). Modernidad, razón e identidad en América Latina, Andrés Bello, Santiago, 1997, pp.167-205.

LUHMANN, N. \& R. DEGIORGI (1993). Teoría de la Sociedad. Universidad de Guadalajara. Universidad I beroamericana. Instituto Tecnológico y de Estudios Superiores de Occidente, México

MASCAREÑO, A. (2001). La Reinvención del Futuro: Objeciones estructurales del tránsito hacia la sociedad del conocimiento en Chile. Revista Persona y Sociedad, Octubre 2001. Santiago: Universidad Alberto Hurtado.

MARGULIS, M, (2005, Febrero 25). Globalización y Cultura.

Recuperado el 15 de septiembre de 2005, de

http://www.gobernabilidad.cl/modules. php?name=News\&file=article\&sid=781.

MINISTERIO ECONOMÍA, (2004). Texto refundido, coordinado y sistematizado de la Ley № 18.892, de 1989 y sus modificaciones, Ley General de Pesca y Acuicultura. Valparaíso, 28 de septiembre de 1991.

Recuperado el 15 de julio de 2004, de http://www.economía.cl. 
MOULIÁN, T. (2001). Chile: Anatomía de un Mito. Capítulo Tercero: Paraíso del Consumidor. Editorial LOM, Santiago, 2001.

OSORIO, F. (editor), (2004). Ensayos sobre Socioautopoiesis y Epistemología Constructivista. Facultad de Ciencias Sociales, Universidad de Chile. Ediciones MAD, Santiago de Chile.

PALACIOS, A. (2000). El enfoque hermenéutico en la interpretación. Leído en la sesión científica de la Asociación Psicoanalítica Mexicana, el 24 de junio del 2000. México, D. F.

Recuperado el 8 de noviembre de 2004, de http://aom.orgmx/dreamweaver/publicaciones/2000/12/El\%20enfoque\% 20hermeneuti co.html

PNUD, (2002). Informe de Desarrollo Humano en Chile: Nosotros los chilenos: un desafío cultural.

Recuperado el 28 de julio de 2005, de http://www.desarrollohumano.cl

PNUD, (1998). Informe sobre desarrollo humano en Chile, Recuperado el 28 de julio de 2005, de http://www.desarrollohumano.cl/inf98.htm

PNUD, (1996). Informe sobre desarrollo humano en Chile, Recuperado el 28 de julio de 2005, de http://www.desarrollohumano.cl/inf96.htm

RAMíREZ, A., (2001) Modernización de la gestión pública .El caso chileno (1994 2000) Estudio de caso № 58, Magíster en Políticas Públicas. Universidad de Chile. Facultad de Ciencias Físicas y Matemáticas. Departamento de Ingeniería Industrial.

RECASENS, A., (2003). Pueblos de mar. Relatos etnográficos. Ediciones Departamento de Antropología. Facultada de Ciencias Sociales. Universidad de Chile. Bravo y Allende editores. Santiago de Chile.

RODRÍGUEZ, D \& TORRES, J. (2003). Autopoiesis, la unidad de una diferencia: Luhmann y Maturana. Dossie. Sociologías, porto Alegre, año 5, № 9, p. 106-140.

RODRÍGUEZ LARRETA, E. (2005). Cultura e Hibridación: sobre algunas fuentes latinoamericanas.

Recuperado el 2 de noviembre de 2005, de http://hum.gu.se/institutioner/romanskasprak/iberoamerikanskainstitutet/publikatione r/anales/anales7/larreta.pdf

RUíZ, A., (2002). Los aportes de Humberto Maturana a la psicoterapia. Instituto de Terapia Cognitiva, INTECO, Santiago de Chile.

Recuperado el 5 de marzo de 2007, de http://www.inteco.cl/articulos/003/texto_esp.htm

RUIZ, J. (1999). Metodología de la investigación cualitativa ( $2^{\circ}$ ed.). Universidad de Deusto, Bilbao. Segunda parte. La construcción del texto cualitativo, pp. 121-210. 
SALAZAR, G. \& PINTO, J., (1999). Historia Contemporánea de Chile. Volúmen I. Estado, legitimidad, ciudadanía. Serie historia, LOM Ediciones. Primera edición: abril 1999, Santiago de Chile, pp. 99-123.

SANTIBÁÑEZ, D. (2000). Estrategia de Modernización de la Gestión Pública: El Paradigma de la Racionalidad Económica y la Semántica de la Eficiencia. Revista Mad. No.3. Septiembre 2000. Departamento de Antropología. Universidad de Chile. Recuperado el 4 de septiembre de 2005, de http://rehue.csociales. uchile.cl/publicaciones/mad/03/paper06.htm.

\author{
SERNAPESCA, (2006). Regulación sectorial. Desembarque algas. \\ Recuperado el \\ 30 de abril de 2006, de http://www.sernapesca.cl
}

SOLÉ, C. (1998). Modernidad y Modernización, Anthropos, Barcelona, 1998. 4. La Modernización desde una perspectiva antropológica.

TIRONI, E. (1990). Autoritarismo, modernización y marginalidad. El caso de Chile 1973-1989. Sur Ediciones, pp. 228-280.

TIRONI, E. (1999). La irrupción de las masas y el malestar de las élites. Cap. 1. el espíritu de los 90. Grijalbo, pp. 15-37

\title{
Notas
}

\footnotetext{
1 Es el lado externo del saber, referido a vacíos temporales (saber anticuado) y espaciales (saber inadecuado) de él.

2 Tal como lo señala el Programa de las Naciones Unidas para el Desarrollo, en el Informe "Desarrollo Humano en Chile, 1998 y 1996, que da cuenta de las paradojas de la modernización. La modernidad se encuentra cruzada por varias tensiones. Una de sus características sobresalientes es la tensión entre la modernización y la subjetividad. Como es sabido, por modernización se entiende la expansión del cálculo medios-fines a los diversos campos de la vida social. El despliegue de esta racionalidad instrumental es lo que otorga a la sociedad moderna su eficiencia y dinamismo. Sin embargo, estos criterios se transforman en fines absolutos si no son puestos en relación con la dimensión subjetiva del desarrollo... La subjetividad abarca a la personalidad individual, pero también a sus pautas socioculturales y su sociabilidad cotidiana. A la par con esta relación entre modernización y subjetividad cabe resaltar una segunda tensión. Otro rasgo característico de la modernidad reside en el proceso de diferenciación. Este implica, en lo subjetivo, el desarrollo de la individualidad en sus múltiples modalidades. En lo objetivo, significa la diferenciación de los distintos campos sociales, por ejemplo, la economía, la educación, la salud, la previsión, la ciencia, el derecho, como "sistemas funcionales" (PNUD, 1998)

3 Según el PNUD (1998), en el desarrollo histórico de la sociedad moderna, estas tensiones generan amenazas y oportunidades. Un polo puede distorsionar, anular o subordinar al otro polo de la tensión. También se pueden articular las diferentes tendencias de modo que sus potencialidades se complementen. A esa complementariedad entre modernización y subjetividad, entre las tendencias de diferenciación e integración apunta la noción de Seguridad Humana.

${ }^{4}$ Un ejemplo respecto de programas que se hayan implementado por parte de organismos públicos en el caso de Caleta los Bronces, lo constituye el proyecto del Fondo de Fomento para la Pesca Artesanal, denominado “Equipamiento, Capacitación y Asistencia Técnica para el Fortalecimiento Organizacional, Búsqueda Nuevos Mercados y Comercialización en forma Asociativa para las Caletas Los Bronces, Angosta y Carrizal Bajo". "El proyecto tuvo un costo de M\$ 9.720.- de los cuales M\$ 972 fueron aportados por las organizaciones beneficiarias. El programa persigue aumentar el poder de negociación de los sindicatos para
} http://www.revistamad.uchile.cl/16/marin_06.pdf 
la comercialización de sus productos (algas), de manera de generar oportunidades de negocios y aumentar la cartera de clientes" (Gobierno de Chile, SERNAPESCA, 2005, p.4).

Revista Mad. N 17, Septiembre de 2007. Departamento de Antropología. Universidad de Chile 